\title{
Very Early Anthropometric Changes After Antiretroviral Therapy Predict Subsequent Survival, in Karonga, Malawi
}

\author{
David Maman ${ }^{*}, 1,2$, Judith R. Glynn ${ }^{3}$, Amelia C. Crampin ${ }^{3}$, Katharina Kranzer ${ }^{3}$, Jacqueline Saul ${ }^{3}$, \\ Andreas Jahn ${ }^{3}$, Venance Mwinuka ${ }^{4}$, Msenga H.C. Ngwira ${ }^{5}$, Hazzie Mvula ${ }^{4}$, Fipson Munthali ${ }^{5}$ \\ and Nuala McGrath ${ }^{3,6}$
}

\author{
${ }^{1}$ Hospices Civils de Lyon, Service de Biostatistique, Lyon, F-69003, France; Université de Lyon, Lyon, F-69000, \\ France; Université Lyon I, Villeurbanne, F-69100, France; CNRS UMR5558, Laboratoire de Biométrie et Biologie \\ Evolutive, Equipe Biostatistique Santé, Pierre-Bénite, F-69310, France \\ ${ }^{2}$ Epicentre, Paris, France \\ ${ }^{3}$ London School of Hygiene and Tropical Medicine; London, UK \\ ${ }^{4}$ Karonga Prevention Study, Malawi \\ ${ }^{5}$ Karonga District Hospital, Karonga, Malawi \\ ${ }^{6}$ Africa Centre for Health and Population Studies, University of KwaZulu Natal, Mtubatuba, South Africa
}

\begin{abstract}
Background: Antiretroviral (ART) scale-up in Malawi has been achieved on a large scale based mainly on clinical criteria. Simple markers of prognosis are useful, and we investigated the value of very early anthropometric changes in predicting mortality.

Methods: Principal findings: Adult patients who initiated ART in Karonga District, northern Malawi, between September 2005 and August 2006 were included in a prospective cohort study, and followed for up to one year. We used Cox regression to examine the association between anthropometric changes at 2 and 6 weeks and deaths within the first year.

573 patients were included, of whom 59\% were women; the median age at initiation was 37 and $64 \%$ were in WHO stage 4. Both body mass index (BMI) and mid-upper arm circumference (MUAC) increased linearly with increased time on ART, and were closely correlated with each other. There were 118 deaths. After 2 weeks on ART, a BMI increase of $<0.5$ $\mathrm{kg} / \mathrm{m}^{2}$ (HR 2.47, 95\%CI 1.24-4.94, $\mathrm{p}=0.005$ ) or a MUAC increase of $<0.5 \mathrm{~cm}$ (HR 2.79, 95\%CI 1.19-6.55, $\mathrm{p}=0.008$ ) were strong predictors of death, and these associations were stronger after adjusting for baseline charactertistics. Similar results were found after 6 weeks on ART.

Conclusions: Very early anthropometric changes, after 2 and 6 weeks on ART, are strong predictors of survival, independent of baseline characteristics. This should help identify patients requiring more detailed assessment where facilities are limited. MUAC is particularly valuable, requiring the simplest equipment and being appropriate for patients who have problems standing.
\end{abstract}

Keywords: Anthropometric measure, antiretroviral therapy, HIV, Mortality, sub-Saharan Africa.

\section{INTRODUCTION}

The HIV epidemic has affected Karonga district, Malawi since the early 1980s [1]. The HIV prevalence among adults aged $15-45$ rose from $2.1 \%$ in 1990 to $11.9 \%$ in $2007[2]$. In 2004, Malawi began a rapid scale-up program, using clinical criteria for antiretroviral therapy (ART) eligibility and follow-up when CD4 cell counts were not available [3]. By the end of 2007, more than 100,000 patients were receiving treatment. ART dramatically improved the prognosis, however mortality within the first months of treatment

*Address correspondence to this author at the Epicentre - Médecins Sans Frontières, 8 Rue Saint Sabin, 75011 Paris, France; Tel: +33 (0)1 40.21.55.18; Fax: +33 (0)1 40.21.55.00;

E-mail: david.maman@epicentre.msf.org initiation remained high, as shown in other studies from lowincome countries [4-6].

Among clinical criteria, anthropometric measurements play an important role in the initial assessment of the patient. Low Body Mass Index (BMI) at the initiation of ART has been shown to be a strong predictor of death [7-10]. However, few studies describe anthropometric changes in patients after initiation of ART [11]. In a study in Abidjan, Ivory Coast, the mean BMI increase was modified by baseline BMI values, and anthropometric change was a strong predictor of virological response [11]. Two recent studies found an association between anthropometric changes at 3 and 6 months and mortality [12,13]. However, information on the relationship between earlier anthropometric changes and mortality is lacking. 
First line ART in Malawi uses triple-therapy which includes a fixed dose of Nevirapine. With this treatment regimen, the patient only receives half a dose of Nevirapine for the first 2 weeks to reduce the risk of a hypersensitivity reaction. The dose is doubled after a 2-week check-up to make sure there are no side effects. This makes the 2-week consultation time critical for the assessment of the patient's recovery, treatment adherence and potential side-effects.

Mid-upper arm circumference (MUAC) is a less common tool than BMI to monitor nutritional status of HIV-infected patients on ART. One study found MUAC at treatment initiation to be a predictor of death [14], but no other studies examining MUAC changes have been done. However MUAC is a potentially useful indicator, requiring only a cheap, widely available and durable measuring tape, that requires no calibration, and having the advantage that it can be measured in patients who have difficulty standing.

The aim of this analysis is to describe early anthropometric changes after ART initiation, and explore the association between absolute anthropometric changes after 2 weeks and 6 weeks on ART with mortality.

\section{METHODS}

\section{Setting}

The Karonga Prevention Study was established in 1979 in the rural district of Karonga in northern Malawi. A demographic surveillance system was initiated in 2002 and studies on HIV, tuberculosis and pneumococcal disease are ongoing. An ART clinic, known as the Buyu clinic [15], first opened at the Karonga district hospital on June 22, 2005, as a part of a government initiative to scale up ART access across the country [3]. The initial government target for this clinic was to start up to 50 patients per month on ART, in addition to the "transferred in" patients who had already initiated treatment elsewhere.

\section{Study Population}

HIV positive patients who came for screening at the Buyu clinic between September 12, 2005 and August 31, 2006 were asked if they would take part in a study on access, uptake and outcome of ART. Patients attending the clinic in this period were included in the study if: (a) they initiated ART based on a fixed dose combination of Stavudine, Lamivudine and Nevirapine; (b) they had not had prior ART treatment when they joined the clinic (apart from Nevirapine for prevention of mother-to-child transmission); (c) they agreed to participate and gave their written consent; and (d) they were above the age of 14 years at the time of initiation. Patients started treatment based on clinical criteria, if they were WHO stage three or four, or had a CD4 count $<250$ cells $/ \mu 1$ (if available), following Malawi Government guidelines.

\section{Outcomes and Exposures}

Death was either reported by relatives/friends of the patients or was identified via a tracking team employed by the study. The team visited the patients' home if they were more than 10 days late for a clinic appointment.

The height of every patient was measured during the first consultation. Weight and the MUAC were measured at every consultation. BMI is defined as weight in kilograms divided by the squared height in meters. The WHO defines Chronic Energy Deficiency (CED) in adults [16] as mild if the BMI lies between 17 and $18.4 \mathrm{~kg} / \mathrm{m}^{2}$, severe if it is between 16 and $16.9 \mathrm{~kg} / \mathrm{m}^{2}$ and very severe if the BMI is below 16 $\mathrm{kg} / \mathrm{m}^{2}$. The WHO define CED cut-off points for MUAC at $22 \mathrm{~cm}$ for women and $23 \mathrm{~cm}$ for men [17]. The MUAC was measured to the nearest $0.1 \mathrm{~cm}$ at the midpoint of the upper arm and always measured on the same arm.

BMI and MUAC changes at a particular point in time after ART initiation were categorized as binary variables representing an increase of at least $0.5 \mathrm{~kg} / \mathrm{m}^{2}$ for the BMI, and of at least $0.5 \mathrm{~cm}$ for MUAC. These cut-off points were chosen to ensure a minimum number of patients (at least $30 \%$ ) in each category at any point in time. No guidance for different cut-offs could be found in the literature. We chose to use absolute changes rather than relative changes, as this enables the development of practical clinical recommendations for clinicians and others to use during patient follow-up.

\section{Statistical Analysis}

Aggregated means and their $95 \%$ confidence intervals for anthropometric changes at different time points after ART initiation were calculated. Means and medians were close, as BMI and MUAC were normally distributed, so means and confidence intervals are presented throughout. The correlation between MUAC and BMI, before and after ART initiation was assessed using Pearson correlation coefficients.

Survival analysis was used to examine the association between baseline and early anthropometric changes (at 2 and at 6 weeks) and death. Two different measures of anthropometric change were considered in the analysis: absolute changes in BMI and MUAC, at the two time points. The association between baseline risk factors and death were estimated using univariate and multivariate Cox regression. Mortality hazard ratios were calculated with $95 \%$ confidence intervals. Likelihood ratio tests were also performed to determine the significance of each factor in the model.

For the baseline analysis, time of entry to the analysis was defined as the day patients initiated ART. To assess the effect of anthropometric changes, time of entry to the analysis was the day the measurement was taken at 2 weeks (or 6 weeks), so only the patients alive at this time point on ART were included in the cohort (left censoring). End of follow-up occurred the day the patient died, the day the patient was transferred out of the program or at the end of the study (end of August 2006).

The association between early anthropometric changes and death was examined by Cox regression, adjusted for baseline BMI (or MUAC), WHO stage, sex and age. We also looked for potential effect modification by baseline anthropometric characteristics by exploring interaction terms and testing their significance using likelihood ratio tests.

The association between missing weights, heights and MUAC with death was examined using multivariate Cox regression, and mortality hazard ratios were calculated at 2 and 6 weeks after initiation of ART. Patients with missing values in these key variables were excluded from the 
analysis. Kaplan-Meier survival curves were used to compare survival by early anthropometric changes at 2 and 6 weeks. The data were analyzed using Stata 10 (Stata Corp., College station, Texas, USA)

\section{Ethics Statement}

The study was approved by the Malawi National Health Sciences Research Committee and the London School of Hygiene \& Tropical Medicine, UK.

\section{RESULTS}

\section{Study population}

As outlined in Fig. (1), 573 patients met the inclusion criteria for the study, giving a total of 174.5 person-years at risk. The median duration of follow-up on ART was 2.86 months (InterQuartile Range IQR 1.38-5.5). Baseline characteristics are displayed in Table 1. Among the 573 patients eligible, $59 \%$ of the participants were women and the median age at initiation was 37.4 years (IQR 31.6; 44.6). 237 patients (41\%) were farmers and 165 (29\%) had received more than 10 years of education. At initiation, 369 patients $(64 \%)$ were Stage 4 according to the WHO scale.

\section{Anthropometry}

The mean BMI and MUAC at baseline were $18.6 \mathrm{~kg} / \mathrm{m}^{2}$ (95\% CI 18.4 to 18.8 ) and $22.8 \mathrm{~cm}$ (95\%CI 22.6 to 23.1 ) respectively. The mean changes of BMI and MUAC initially followed a linear trend with time on ART (Fig. 2). The mean increase in BMI was $0.15 \mathrm{~kg} / \mathrm{m}^{2}$ (446 observations, $95 \% \mathrm{CI}$ 0.07 to 0.22 ) at 2 weeks, $0.45 \mathrm{~kg} / \mathrm{m}^{2}$ (346 observations, $95 \%$ CI 0.33 to 0.58$)$ at 6 weeks and $1.58 \mathrm{~kg} / \mathrm{m}^{2}(111$ observations, $95 \%$ CI 1.25 to 1.92 ) at 6 months after ART initiation (Fig. 2). The mean MUAC change was $-0.06 \mathrm{~cm}$ (444 observations, 95\%CI -0.29 to 0.01 ) after 2 weeks on ART, $0.12 \mathrm{~cm}$ (346 observations, $95 \% \mathrm{CI}-0.04$ to 0.29 ) at 6 weeks and $1.24 \mathrm{~cm}$ at 6 months (111 observations, 95\% CI 0.87 to 1.62 ). Using all measurements taken across time points (giving 2492 observations), the Pearson correlation coefficient was 0.86 between the values of BMI and MUAC, suggesting a strong correlation between the two indicators.

\section{Survival Analysis}

During follow-up, 118 patients died. Among them, 26, 46 and 45 deaths happened during the first 2 weeks, between 2 and 6 weeks and between 6 weeks and 6 months after ART

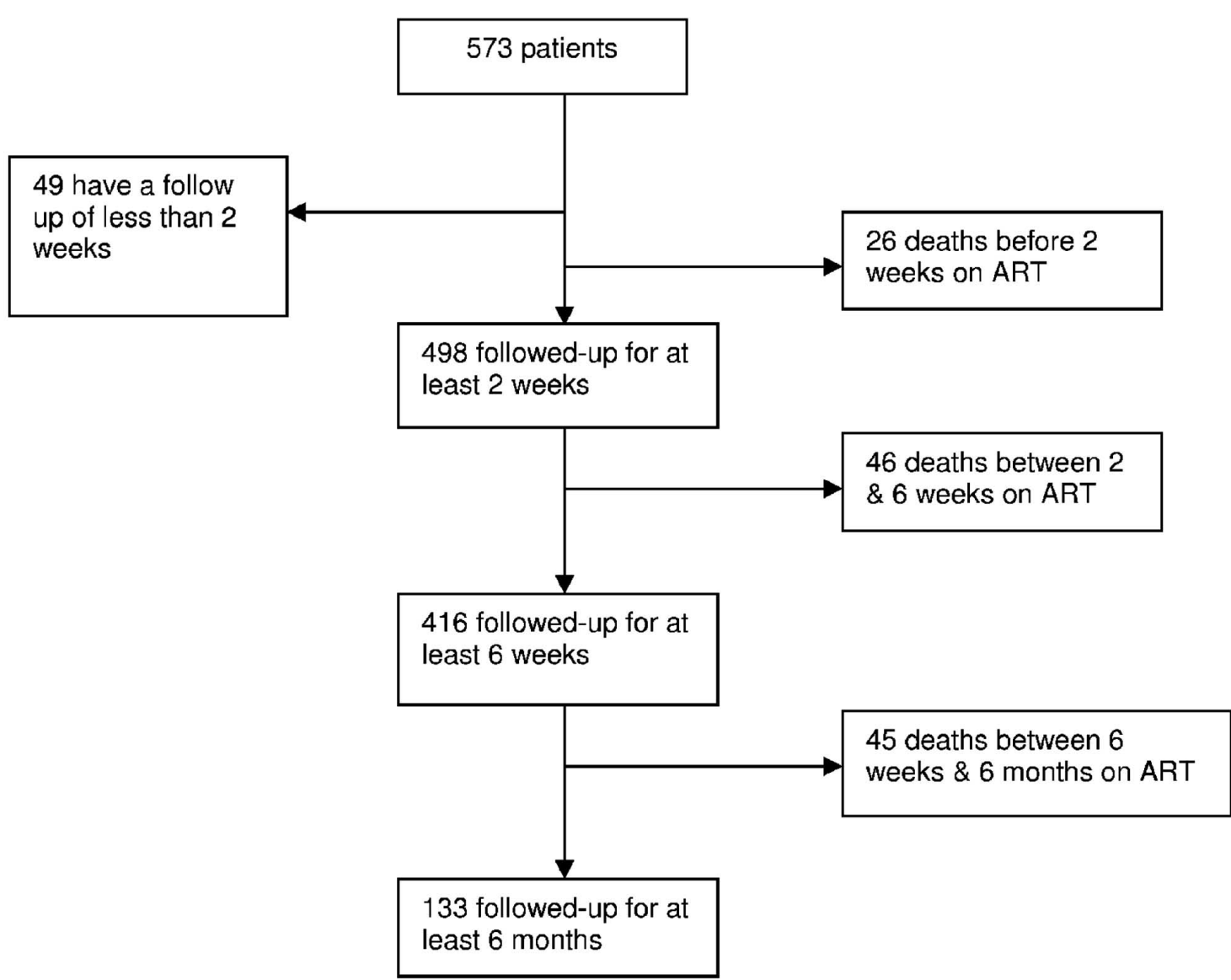

Fig. (1). Patients flowchart. 
Table 1. Patient Characteristics at ART Initiation

\begin{tabular}{|c|c|}
\hline Characteristics & Overall (\%) (Total 573) \\
\hline \multicolumn{2}{|l|}{ Sex } \\
\hline Female & $338(59)$ \\
\hline Male & $235(41)$ \\
\hline \multicolumn{2}{|l|}{ Age (years) } \\
\hline$<25$ & $40(7)$ \\
\hline 25 and 35 & $206(36)$ \\
\hline 35 and 45 & $193(34)$ \\
\hline$>45$ & $134(23)$ \\
\hline \multicolumn{2}{|c|}{ Education (in Years of School) (Missing 5) } \\
\hline 0 & $29(5)$ \\
\hline Between 1 and 4 & $75(13)$ \\
\hline Between 5 and 9 & $299(29)$ \\
\hline 10 or more & $165(29)$ \\
\hline \multicolumn{2}{|l|}{$\begin{array}{l}\text { Occupation } \\
\text { (Missing : 4) }\end{array}$} \\
\hline Farmer & $237(41)$ \\
\hline Other & $194(34)$ \\
\hline No occupation & $138(24)$ \\
\hline \multicolumn{2}{|l|}{ Marital Status } \\
\hline Divorced & $117(20)$ \\
\hline Married & $276(48)$ \\
\hline Single & $21(4)$ \\
\hline Widowed & $159(28)$ \\
\hline \multicolumn{2}{|l|}{ WHO Stage } \\
\hline Stage2 & $6(1)$ \\
\hline Stage 3 & $198(35)$ \\
\hline Stage 4 & $369(64)$ \\
\hline \multicolumn{2}{|c|}{ Body Mass Index (Kg/m²) (Missing: 4) } \\
\hline$>=18,5$ & $297(52)$ \\
\hline Between 17 and 18,5 & 109(19) \\
\hline Between 16 and 17 & $72(13)$ \\
\hline$<16$ & $91(16)$ \\
\hline \multicolumn{2}{|l|}{ MUAC } \\
\hline No CED* & $320(56)$ \\
\hline CED & $253(44)$ \\
\hline
\end{tabular}

initiation, respectively. Kaplan Meier estimates for survival were $0.95(95 \% \mathrm{CI} 0.93$ to 0.97$)$ at 2 weeks, $0.87(95 \% \mathrm{CI}$ 0.83 to 0.89$)$ after 6 weeks and $0.75(95 \% \mathrm{CI} 0.70$ to 0.79$)$ after 6 months on ART.

\section{Association Between Baseline Characteristics and Death}

In a univariate analysis, men, and those with initial WHO stage 4, lower baseline BMI, and lower baseline MUAC, had higher mortality rates. In the multivariate analysis, except gender, these variables remained associated with death after adjustment (Table 2).

\section{Missing Values}

Among the 517 patients who came to the clinic for their visit 2 weeks after ART initiation, 74 had missing BMI and 70 missing MUAC values (70 patients were missing both). The patients with missing measurements had a higher rate of death compared to those who had these measurements: for BMI, HR 2.57; 95\%CI 1.57 to 4.22, Likelihood ratio test (LRT) $\mathrm{p}<0.001$; for MUAC, HR 2.57; 95\%CI 1.57 to 4.22; LRT $\mathrm{p}<0.001$. The association was similar for patients who had missing values at 6 weeks on ART for BMI (59 missing, HR 2.32; 95\%CI 0.90; 6.01; LRT $\mathrm{p}=0.08)$ and MUAC (58 missing, HR 2.40; 95\%CI 0.92; 6.28; LRT p=0.07) (Table 3).

\section{Association Between Early Anthropometric Changes and Death}

After 2 weeks on ART, a BMI increase of less than 0.5 $\mathrm{kg} / \mathrm{m}^{2}$ was strongly associated with higher subsequent mortality (Table 4). The association was stronger after adjusting for sex, age, baseline categories of BMI, and WHO initial stage, (HR 2.47, 95\%CI 1.24 to $4.93, \mathrm{p}=0.005$ ). The effect was similar by different baseline categories of BMI (LRT for interaction $\mathrm{p}=0.69$ ). Similar results were found when a 2-week MUAC increase of less than $0.5 \mathrm{~cm}$ was considered (HR 2.78 95\%CI 1.19 to $6.53 \mathrm{p}=0.008$ ).

After 6 weeks on ART, a BMI increase of less than $0.5 \mathrm{~kg} / \mathrm{m}^{2}$ was associated with a 3 times higher mortality on univariate and multivariate analysis (HR 3.41 95\%CI 1.24 to 9.39 LRT $\mathrm{p}=0.01)$. MUAC change of less than $0.5 \mathrm{~cm}$ at 6 weeks was also associated with increased mortality (HR 2.34 95\%CI 0.85 to 6.39, LRT $\mathrm{p}=0.078$ ), albeit not statistically significant.

The combined effect of baseline and 2-week changes of anthropometric measures on mortality over time are presented in Figs. $(3,4)$. For those with a baseline BMI $<18.5 \mathrm{~kg} / \mathrm{m}^{2}$, failure to recover at least $0.5 \mathrm{~kg} / \mathrm{m}^{2}$ after 2 weeks on ART was associated with much worse survival: the Kaplan Meier estimate for survival at 3 months was 0.73 (95\% CI 0.63 to $0.81)$, compared to 0.85 (95\% CI 0.72 to 0.92 ) in those who had gained at least $0.5 \mathrm{~kg} / \mathrm{m}^{2}$. For those with a baseline BMI of at least $18.5 \mathrm{~kg} / \mathrm{m}^{2}$ failure to increase their BMI by at least 0.5 $\mathrm{kg} / \mathrm{m}^{2}$ after 2 weeks under treatment was also associated with worse survival (Fig. 3), compared to very few deaths in those who increased their BMI (3 month survival estimate 0.99 (95\% CI 0.90 to 1)). Similar trends are found when baseline MUAC and 2-week changes are considered (Fig. 4). Those with CED at baseline who failed to recover $0.5 \mathrm{~cm}$ of MUAC after 2 weeks of ART experienced worse survival than who had gained at least $0.5 \mathrm{~cm}$, with a Kaplan Meier estimate for survival at 3 months of $0.74(95 \% \mathrm{CI} 0.64$ to 0.82$)$ and $0.93(95 \% \mathrm{CI} 0.88$ to 0.96) respectively. For those with no CED at time of ART start, the estimate survival at 3 months was 0.98 (95\%CI 0.89 to 1$)$ for those who recovered at least $0.5 \mathrm{~cm}$ of MUAC after 2 weeks of ART.

\section{DISCUSSION}

Anthropometric changes at 2 and 6 weeks are strong predictors of survival after initiation of ART, independent of baseline measurements. Baseline anthropometric status did not modify the association between these changes and 


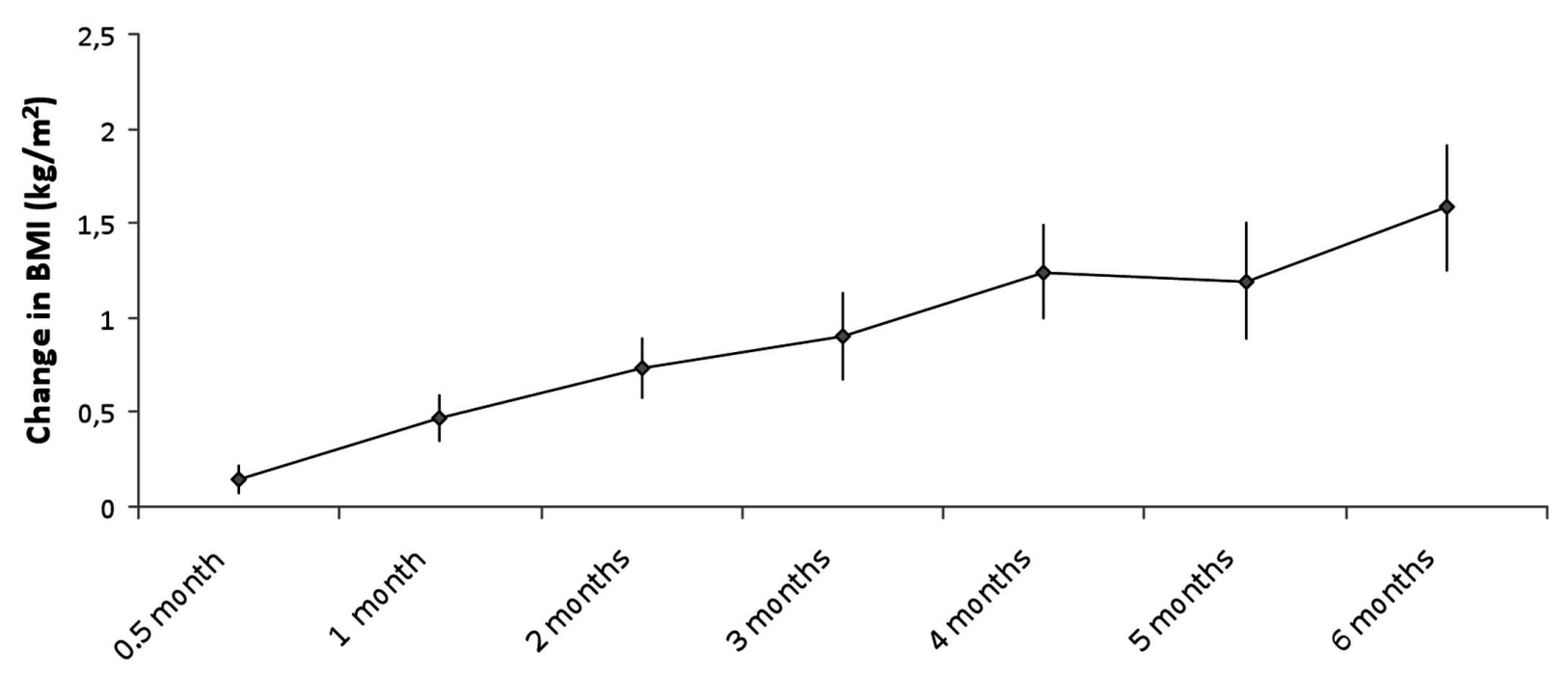

Time on ART by categories

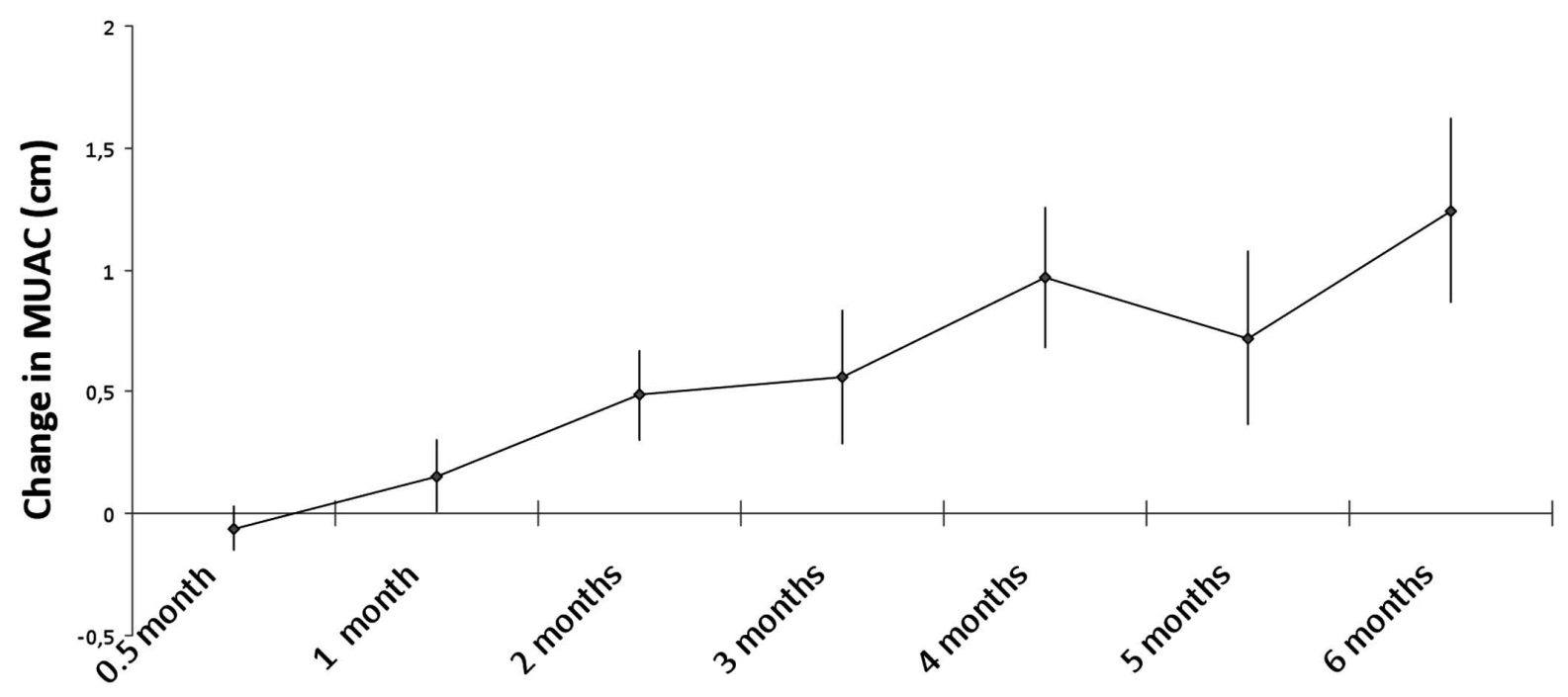

Time on ART by categories

Fig. (2). (a, b) Mean MUAC and BMI changes by time on ART.

mortality. Although two previous studies have provided evidence of the prognostic values of anthropometric changes after 3 and 6 months on ART $[12,13]$, none has examined this association for earlier anthropometric changes, when the mortality rate is generally higher.

These findings can help identify patients at risk, allowing further investigation of, for example: whether patients have an adherence problem, the deterioration of tuberculosis or another opportunistic infection, a hypersensitivity reaction or an Immune Reconstitution Inflammatory Syndrome. The use of simple cut-off points could be particularly useful in remote areas to detect patients at higher risk of death, and in settings where only clinical follow-up is feasible, and care is usually provided by nurses and other non-physicians facing a high workload. Early anthropometric changes can also be useful to detect patients who are at very low risk of death, in order to use human resources more efficiently, a major concern in these settings. Combining the effects of baseline and 2-week changes of anthropometric measures on ART could be of clinical importance, by, for example, creating a different consultation schedule based on these two predictors.

MUAC appears to be a valuable alternative to BMI for follow-up of anthropometric changes. They are closely 
Table 2. Baseline Characteristics of the Population and Association with Death, Univariate and Multivariate Analysis, Cox Model

\begin{tabular}{|c|c|c|c|c|c|c|c|}
\hline Characteristics & $\begin{array}{l}\text { Overall (\%) } \\
\text { (Total 573) }\end{array}$ & $\begin{array}{c}\text { Deaths } \\
\text { (Total 118) }\end{array}$ & $\begin{array}{c}\text { Y } \\
\text { (Person-Year) }\end{array}$ & $\begin{array}{l}\text { Univariate HR } \$ \\
\quad(95 \% \text { CI) }\end{array}$ & P Value* & $\begin{array}{l}\text { Multivariate HR }+4 \\
\quad(95 \% \text { CI) }\end{array}$ & P Value* \\
\hline \multicolumn{4}{|l|}{ Sex } & & \multicolumn{2}{|l|}{$\mathrm{p}=0.021$} & $\mathrm{P}=0.12$ \\
\hline Female & $338(59)$ & 58 & 104.3 & 1 & & 1 & \\
\hline Male & $235(41)$ & 60 & 70.3 & $1.53(1.07 ; 2.19)$ & & $1.36(0.93 ; 2.00)$ & \\
\hline \multicolumn{5}{|l|}{ Age (years) } & $\mathrm{p}=0.71$ & & $\mathrm{P}=0.07$ \\
\hline$<25$ & $40(7)$ & 7 & 13.5 & 1 & & 1 & \\
\hline 25 and 35 & $206(36)$ & 38 & 59.7 & $1.13(0.50 ; 2.13)$ & & $1.28(0.57 ; 2.87)$ & \\
\hline 35 and 45 & $193(34)$ & 42 & 60.4 & $1.34(0.60 ; 2.98)$ & & $1.89(0.83 ; 4.27)$ & \\
\hline$>45$ & $134(23)$ & 31 & 41.0 & $1.40(0.62 ; 3.18)$ & & $1.74(0.76 ; 4.02)$ & \\
\hline \multicolumn{5}{|l|}{ WHO Stage } & $\mathrm{p}<0.001$ & & $\mathrm{P}=0.008$ \\
\hline Stage $2 * *$ & $6(1)$ & & & & & & \\
\hline Stage 3 & $198(35)$ & 22 & 59.0 & 1 & & 1 & \\
\hline Stage 4 & $369(64)$ & 96 & 113.6 & $2.42(1.53 ; 3.86)$ & & $1.85(1.14 ; 2.99)$ & \\
\hline \multicolumn{4}{|c|}{ Body Mass Index (Kg/m²) (Missing: 4) } & & $\mathrm{p}<0.001$ & & $\begin{array}{c}\mathrm{p}<0.001 \\
\left(p_{\text {trend }}<0.001\right)\end{array}$ \\
\hline$\geq 18.5$ & $297(52)$ & 30 & 100.7 & 1 & & 1 & \\
\hline $17-18.4$ & 109(19) & 21 & 34.9 & $2.13(1.21 ; 3.72)$ & & $1.39(0.75 ; 2.59)$ & \\
\hline $16-16.9$ & $72(13)$ & 19 & 20.52 & $3.01(1.69 ; 5.35)$ & & $1.58(0.78 ; 3.22)$ & \\
\hline$<16$ & $91(16)$ & 45 & 18.1 & $6.86(4.32 ; 10.9)$ & & $3.66(1.90 ; 7.05)$ & \\
\hline MUAC & & & & & $\mathrm{p}<0.001$ & & $\mathrm{P}=0.09$ \\
\hline No CED & $320(56)$ & 31 & 112.4 & 1 & & 1 & \\
\hline CED & $253(44)$ & 87 & 62.1 & $4.48(2.97 ; 6.76)$ & & $2.19(1.21 ; 3.96)$ & \\
\hline
\end{tabular}

*likelihood ratio test.

** Stage 2 and 3 pooled in the analysis.

$\$$ Hazard Ratio.

${ }^{\$}$ Multivariate HR adjusted for all other factors in the table.

Table 3. Association Between Missing Anthropometric Measures and Death Among Patients who Came at their Consultation, Multivariate Cox Regression

\begin{tabular}{|c|c|c|c|c|c|c|c|c|}
\hline & \multicolumn{3}{|c|}{ Missing Values } & \multicolumn{3}{|c|}{ Non Missing Values } & \multirow[t]{2}{*}{ Hazard-Ratio* (95\%CI) } & \multirow[t]{2}{*}{ p-Value** } \\
\hline & $\mathbf{N}$ & Deaths & PY & $\mathbf{N}$ & Deaths & PY & & \\
\hline At 2 weeks & 71 & 27 & 18.3 & 446 & 54 & 150.6 & $2.57(1.57 ; 4.22)$ & $\mathrm{p}<0.001$ \\
\hline At 6 weeks & 59 & 6 & 38.7 & 346 & 22 & 239.6 & $2.32(0.90 ; 6.01)$ & $\mathrm{p}=0.082$ \\
\hline At 2 weeks & 70 & 27 & 18.6 & 447 & 54 & 150.3 & $2.57(1.57 ; 4.22)$ & $\mathrm{p}<0.001$ \\
\hline At 6 weeks & 58 & 6 & 19.7 & 347 & 22 & 139.0 & $2.40(0.92 ; 6.28)$ & $\mathrm{p}=0.072$ \\
\hline
\end{tabular}

*Adjusted by baseline BMI, WHO stage, age and gender.

$* *$ Wald test.

correlated and MUAC is simple and can be an easier tool especially for patients who cannot stand, or get their weight or height checked easily, although training is required to ensure that the MUAC is measured accurately. It could also be used for home-based care, as the measuring tapes are easy to carry. However, there will be times when it is not appropriate, for example, a patient might have an oedema of the arm where the MUAC is usually measured (e.g., due to Kaposi sarcoma).

Two weeks after initiation of treatment a significant increase in BMI was noted, highlighting the rapid effect of treatment and the associated programme of care on patients' recovery. Although the mean MUAC of the patients did not increase at 2 weeks, unlike BMI, changes in MUAC and 
Table 4. Association Between Early Anthropometric Changes and Death, Univariate and Multivariate Analysis, Cox Regression

\begin{tabular}{|c|c|c|c|c|c|c|c|}
\hline & & $\mathbf{N}$ & Deaths & HR $(95 \%$ CI $)$ & $P$ - Value* & $\mathrm{HR}^{* *}(95 \% \mathrm{CI})$ & P-Value* \\
\hline \multicolumn{8}{|l|}{ BMI } \\
\hline \multirow[t]{2}{*}{2 weeks (Missing 71) } & $<0.5 \mathrm{~kg} / \mathrm{m}^{2}$ & 306 & 44 & $2.18(1.10 ; 4.34)$ & $\mathrm{p}=0.002$ & $2.47(1.24 ; 4.93)$ & $\mathrm{P}=0.005$ \\
\hline & $\geq 0.5 \mathrm{~kg} / \mathrm{m}^{2}$ & 140 & 10 & 1 & & & \\
\hline \multirow[t]{2}{*}{6 weeks (Missing 59) } & $<0.5 \mathrm{~kg} / \mathrm{m}^{2}$ & 180 & 17 & $2.80(1.04 ; 7.61)$ & $\mathrm{p}=0.028$ & $3.41(1.24 ; 9.39)$ & $\mathrm{P}=0.01$ \\
\hline & $\geq 0.5 \mathrm{~kg} / \mathrm{m}^{2}$ & 166 & 5 & 1 & & & \\
\hline \multicolumn{8}{|l|}{ MUAC } \\
\hline \multirow[t]{2}{*}{2 weeks (Missing 73) } & $<0.5 \mathrm{~cm}$ & 323 & 46 & $2.71(1.16 ; 6.37)$ & $\mathrm{p}=0.009$ & $2.78(1.18 ; 6.53)$ & $\mathrm{P}=0.008$ \\
\hline & $\geq 0.5 \mathrm{~cm}$ & 121 & 6 & 1 & & & \\
\hline \multirow[t]{2}{*}{6 Weeks (Missing 59) } & $<0.5 \mathrm{~cm}$ & 203 & 17 & $2.18(0.81 ; 5.93)$ & $\mathrm{p}=0.10$ & $2.34(0.85 ; 6.39)$ & $\mathrm{P}=0.078$ \\
\hline & $\geq 0.5 \mathrm{~cm}$ & 143 & 5 & 1 & & & \\
\hline
\end{tabular}

* Likelihood ratio test.

** Adjusted for sex, age, baseline HIV stage, baseline BMI for BMI changes and baseline MUAC for MUAC changes.
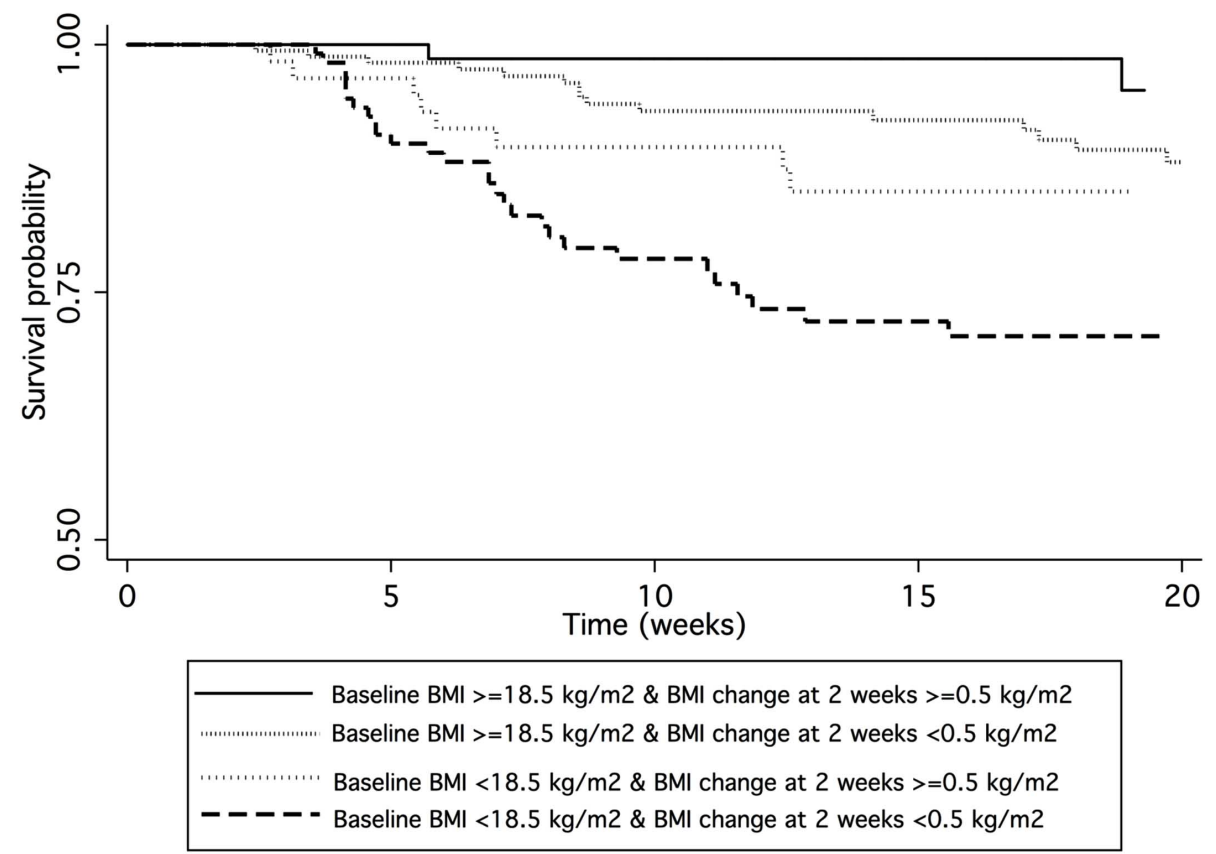

\begin{tabular}{|c|c|c|c|c|c|}
\hline & \multicolumn{5}{|c|}{ Time on ART (Weeks) } \\
\hline & 0 & 5 & 10 & 15 & 20 \\
\hline \multicolumn{6}{|l|}{ Baseline $B M \mid>=18.5 \mathrm{~kg} / \mathrm{m}^{2}$} \\
\hline 2 weeks BMI change $>=0.5 \mathrm{~kg} / \mathrm{m}^{2}$ & 74 & 71 & 56 & 41 & 26 \\
\hline 2 weeks BMI change $<0.5 \mathrm{~kg} / \mathrm{m}^{2}$ & 180 & 161 & 129 & 95 & 71 \\
\hline \multicolumn{6}{|l|}{ Baseline $B M I<18.5 \mathrm{~kg} / \mathrm{m}^{2}$} \\
\hline 2 weeks $B M I$ change $>=0.5 \mathrm{~kg} / \mathrm{m}^{2}$ & 66 & 57 & 47 & 32 & 27 \\
\hline 2 weeks BMI change $<0.5 \mathrm{~kg} / \mathrm{m}^{2}$ & 126 & 100 & 72 & 49 & 37 \\
\hline
\end{tabular}

Fig. (3). Kaplan-Meier survival by Baseline BMI and BMI change after 2 weeks on ART. The table shows the number of individuals still being followed at each time point.

BMI at 2 weeks were similarly predictive of subsequent survival. The median MUAC and BMI increase follow a linear trend throughout the first 6 months on ART. After 3 and 6 months on treatment, the mean BMI increase was, respectively, 0.95 and $1.51 \mathrm{~kg} / \mathrm{m}^{2}$; results similar to those found in other studies [11].
The power of the study was not sufficient to investigate a detailed dose response effect of the BMI changes on mortality. As it is the first time such an analysis has been performed, we chose cut-off points to ensure enough patients in each group. Studying changes on a bigger cohort over a longer time could confirm these findings and improve knowledge of the implications of a wider range of 


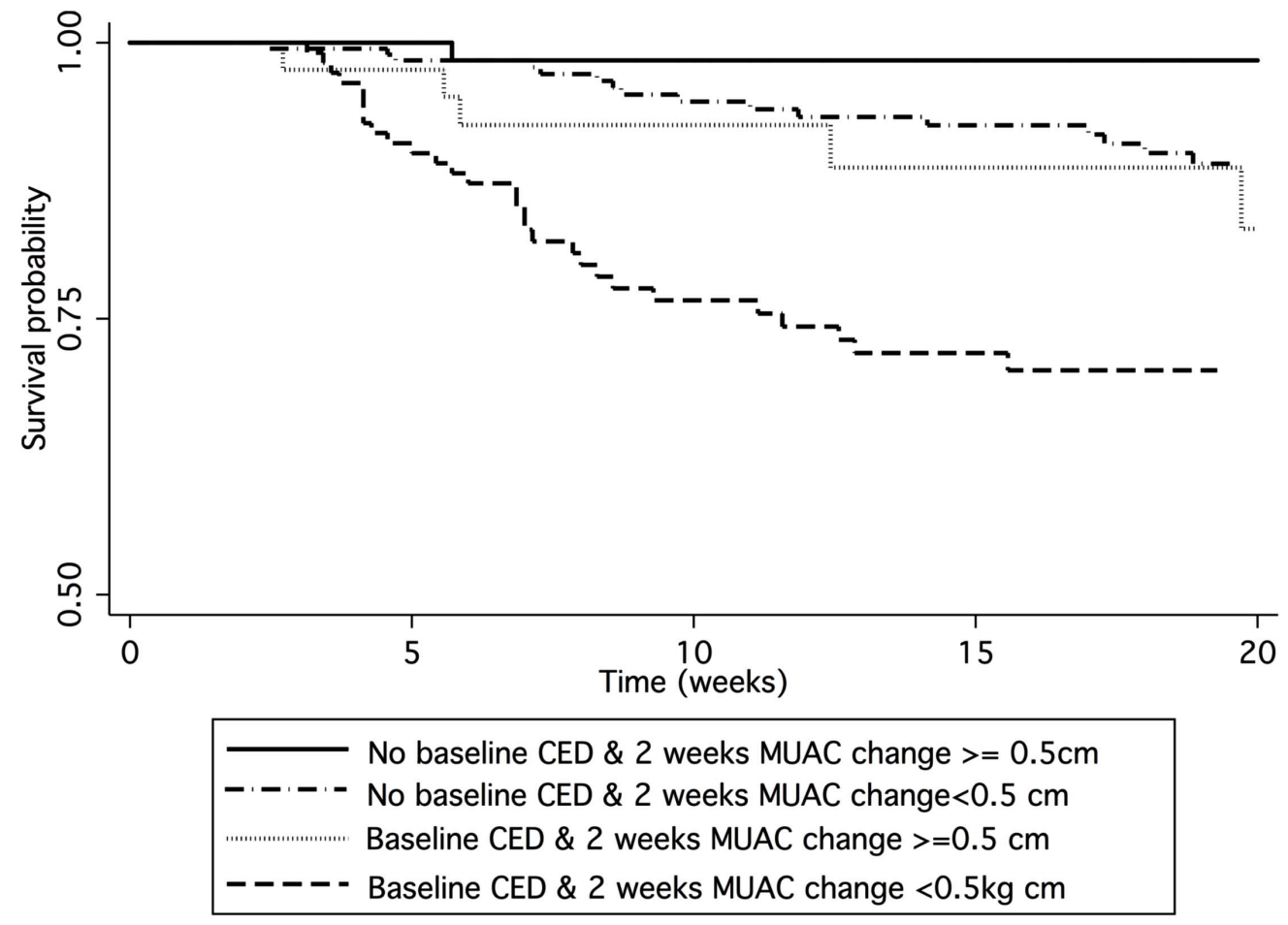

\begin{tabular}{lccccc}
\hline & \multicolumn{5}{c}{ Time on ART (Weeks) } \\
& 0 & 5 & 10 & 15 & 20 \\
\cline { 2 - 6 } No baseline CED & & & & & \\
2 weeks MUAC change $>=0.5 \mathrm{~cm}$ & 71 & 64 & 53 & 37 & 30 \\
2 weeks MUAC change $<0.5 \mathrm{~cm}$ & 204 & 184 & 149 & 113 & 80 \\
Baseline CED & & & & & \\
2 weeks MUAC change $>=0.5 \mathrm{~cm}$ & 50 & 40 & 29 & 18 & 15 \\
2 weeks MUAC change $<0.5 \mathrm{~cm}$ & 119 & 100 & 72 & 49 & 36 \\
\hline
\end{tabular}

Fig. (4). Kaplan-Meier survival by Baseline MUAC and MUAC change after 2 weeks on ART. The table shows the number of individuals still being followed at each time point.

anthropometric changes over a long period of time on ART. The study only continued for one year, thus many of the patients had short follow-up times due to right censoring at the end of the study, not loss to follow-up.

Missing data for patients who came to the clinic were not missing at random and were strongly associated with death. Patients who are unable to stand cannot get their weight measured. Missing data on these patients is likely to have led to underestimation of the effects seen, as patients who are unable to stand are unlikely to have gained weight and probably had a poor prognosis. It is not clear why MUAC was also not measured in these patients. Measurement errors in the BMI and MUAC are also likely to have led to an underestimate in the associations seen as they are likely to have been random. We were unable to assess whether the predictive value of anthropometric changes was independent of changes in known predictors such as CD4 count and viral load. National guidelines allowed clinical staging as criteria sufficient for ART initiation in the absence of CD4 count and no CD4 testing was available at the hospital during the study. Knowing whether anthropometric changes were predictors independently of CD4 and viral load was not the purpose of the analysis, as the criteria are suggested for use in situations which rely on clinical judgement.

This study took place in conditions similar to routine HIV care in rural Malawi. Simple clinical tools to detect patients at higher risk of death just after ART initiation are much needed. We propose appropriate simple tools. It remains to be seen how much identifying those at particular risk can improve their prognosis.

\section{ACKNOWLEDGEMENTS}

The study was designed by $\mathrm{NMcG}, \mathrm{AC}$, and $\mathrm{AJ}$, with contributions from JG and JS. It was carried out by $\mathrm{NMcG}$, AC, AJ, KK, VM, MN, HM, FP. DM, with NMcG and JG, did the analysis, and wrote the first draft. All authors contributed to the interpretation of the findings and drafting of the manuscript. NMcG is the guarantor.

\section{CONFLICT OF INTEREST STATEMENT}

The Karonga Prevention Study is funded by The Wellcome Trust, with contributions from LEPRA. This study was in part supported by the World Health Organization, through the Malawi National AIDS Commission. Maman is financially supported by Sidaction, 
France (BI20-3-01644). McGrath was supported by the Wellcome Trust, UK (WT083495MA). The funders had no role in study design, data collection and analysis, decision to publish, or preparation of the manuscript.

The authors declare that they have no conflict of interest with respect to this paper.

\section{REFERENCES}

[1] Glynn JR, Ponnighaus J, Crampin AC, et al. The development of the HIV epidemic in Karonga District, Malawi. AIDS 2001; 15(15): 2025-9.

[2] UNAIDS. Report on the Global AIDS Epidemic. Geneva: UNAIDS 2008.

[3] Treatment of AIDS : The 2 year plan to scale up antiretroviral therapy in Malawi. Ministryn of Health and population, Malawi; 2004 February 2004.

[4] Ferradini L, Jeannin A, Pinoges L, et al. Scaling up of highly active antiretroviral therapy in a rural district of Malawi: an effectiveness assessment. Lancet 2006; 367(9519): 1335-42.

[5] Coetzee D, Hildebrand K, Boulle A, et al. Outcomes after two years of providing antiretroviral treatment in Khayelitsha, South Africa. AIDS 2004; 18(6): 887-95.

[6] Toure S, Kouadio B, Seyler C, et al. Rapid scaling-up of antiretroviral therapy in 10,000 adults in Cote d'Ivoire: 2-year outcomes and determinants. AIDS 2008; 22(7): 873-82.

[7] Bussmann H, Wester CW, Ndwapi N, et al. Five-year outcomes of initial patients treated in Botswana's National Antiretroviral Treatment Program. AIDS 2008; 22(17): 2303-11.

[8] Sieleunou I, Souleymanou M, Schonenberger AM, Menten J, Boelaert M. Determinants of survival in AIDS patients on antiretroviral therapy in a rural centre in the Far-North Province, Cameroon. Trop Med Int Health 2009; 14(1): 36-43.

[9] Zachariah R, Fitzgerald M, Massaquoi M, et al. Risk factors for high early mortality in patients on antiretroviral treatment in a rural district of Malawi. AIDS 2006; 20(18): 2355-60.

[10] Stringer JS, Zulu I, Levy J, et al. Rapid scale-up of antiretroviral therapy at primary care sites in Zambia: feasibility and early outcomes. JAMA 2006; 296(7): 782-93.

[11] Messou E, Gabillard D, Moh R, et al. Anthropometric and immunological success of antiretroviral therapy and prediction of virological success in west African adults. Bull World Health Organ 2008; 86(6): 435-42.

[12] Madec Y, Szumilin E, Genevier C, et al. Weight gain at 3 months of antiretroviral therapy is strongly associated with survival: evidence from two developing countries. AIDS 2009; 27(7): 85361.

[13] Koethe JR, Lukusa A, Giganti MJ, et al. Association between weight gain and clinical outcomes among malnourished adults initiating antiretroviral therapy in Lusaka, Zambia. J Acquir Immune Defic Syndr 2010; 53(4): 507-13.

[14] Gustafson P, Gomes VF, Vieira CS, et al. Clinical predictors for death in HIV-positive and HIV-negative tuberculosis patients in Guinea-Bissau. Infection 2007; 35(2): 69-80.

[15] McGrath N, Glynn JR, Saul J, et al. What happens to ART-eligible patients who do not start ART? Dropout between screening and ART initiation: a cohort study in Karonga, Malawi. BMC Public Health 2010; 10: 601.

[16] James WP, Ferro-Luzzi A, Waterlow JC. Definition of chronic energy deficiency in adults. Report of a working party of the International Dietary Energy Consultative Group. Eur J Clin Nutr 1988; 42(12): 969-81.

[17] WHO. Physical status: the use and interpretation of anthropometry. Report of a WHO Expert Committee. Geneva 1995.

(C) Maman et al.; Licensee Bentham Open.

This is an open access article licensed under the terms of the Creative Commons Attribution Non-Commercial License (http://creativecommons.org/licenses/by-nc/ 3.0/) which permits unrestricted, non-commercial use, distribution and reproduction in any medium, provided the work is properly cited. 